\title{
Estatuto ontológico y ético del feto anencefálico: Una perspectiva filosófica
}

\author{
Mauricio Besio R, Francisca Besio $\mathbf{H}^{\mathrm{a}}$. \\ Ontological and ethical statute \\ of anencephalic fetus
}

Due to advances in prenatal techniques, it is now possible to diagnose malformations in utero, such as anencephaly, which in the past was only known at birth. Having knowledge of a malformation before birth, the moment in which almost every individual obtains social and legal protection, puts the malformed fetus in a vulnerable situation toward possible actions that lead to the interruption of pregnancy. The aim of this article is to analyze different positions about the quality and reality of the anencephalic fetus, its human condition and the care that the fetus and mother deserve (Rev Méd Chile 2008; 136: 783-88).

(Key words: Anencephaly abnormalities; Ethics; Statute)

Recibido el 3 de septiembre, 2007. Aceptado el 10 de enero, 2008.

Departamento de Ginecología y Obstetricia, Centro de Bioética, Pontificia Universidad Católica de Chile. Santiago, Chile.

anterna de VI año de Medicina. Universidad de Chile, Campus Centro.

$\mathrm{E}^{\mathrm{s}}$ sta reflexión se inicia reconociendo que cuando se origina un debate en la sociedad sobre algún problema, habitualmente se debe a que se confrontan maneras diversas de entender la realidad con la cual todos interactuamos. Nos pareció necesario compartir un análisis de un problema que afecta a pacientes y médicos, el del feto anencefálico. Esto, desde una cierta perspectiva filosófica, la realista, que intenta primero determinar a qué tipo de realidad nos enfrentamos, $\mathrm{y}$ desde allí deducir la conducta que esa realidad merecería.

El simple hecho de poder comprobar que una mujer embarazada gesta en su interior un feto con una malformación, que afecta radicalmente su estructura encefálica, parece suscitar un problema, y en el último tiempo han aparecido voces en los medios de comunicación y en instancias legislativas que se refieren a él*. Paradojalmente, el dilema se debe al avance y masificación de las

Correspondencia a: Dr. Mauricio Besio R. Casilla 193, Correo 22 Santiago. E mail: besio@med.puc.cl

\footnotetext{
*Proyecto de Ley que "Protege la vida de la mujer ante intervenciones de embarazo en casos que se indica". Boletín № 4845-11, Cámara de Diputados, República de Chile, 18 de enero de 2007.
} 
técnicas de diagnóstico prenatal, esto por la sencilla razón que se ha trasladado, desde el parto a etapas ahora tempranas del desarrollo fetal, el poder conocer esta característica. En efecto, hasta antes de la ultrasonografía, como posibilidad no invasiva de estudio del feto en el útero materno, el diagnóstico de esta anomalía se realizaba habitualmente en el momento del parto. Esto tiene enorme trascendencia para esta reflexión, ya que traslada la situación desde el momento donde casi universalmente existe una protección social y legal para ese individuo malformado, a otro donde, y aquí está justamente la dificultad, éste está al alcance de acciones que pueden arriesgar sus derechos más elementales.

La ya nombrada anencefalia, en su significado médico, es la ausencia congénita de una parte importante del cerebro y cráneo, producto de una falla en el cierre de la porción cefálica del tubo neural, el que en condiciones normales se cierra a fines del primer mes de un embarazo ${ }^{1,2}$. El rostro de un anencefálico es generalmente de un aspecto normal desde la parte inferior de los ojos hasta el mentón ${ }^{3}$. El diagnóstico ecográfico de esta patología se basa, por lo tanto, en la ausencia de cerebro y huesos del cráneo, y el pronóstico es malo: alrededor del $75 \%$ de estos fetos fallecen in utero $^{3}$. Cuando llegan a nacer, los recién nacidos tienen actividad del tronco encefálico, respiración espontánea y a menudo reflejo de succión, pero se encuentran permanentemente inconscientes. Sin un cuidado intensivo, la mayoría fallece durante los dos primeros días después del nacimiento, y ninguno, según la literatura médica, sobrevive más de algunas semanas ${ }^{2}$. En general, la causa de la anencefalia es desconocida, sugiriéndose eso sí una etiología multifactorial ${ }^{2}$. En Sudamérica se describe una frecuencia de 11,7 por 10.000 nacimientos ${ }^{4}$. En Estados Unidos de Norteamérica, en cambio, tienen una incidencia de 9,4 por 100.000 nacidos vivos, cifra subestimada y muy inferior, debido a los abortos espontáneos y provocados de los fetos afectados ${ }^{2}$.

Ahora bien, ya conocido el término y sin entrar aún a discutir el estatuto ontológico de este feto anencefálico, podemos desde ya vislumbrar un hecho que viene a complicar este problema, $\mathrm{y}$ es que el aborto no es repudiado universalmente como sí lo es el infanticidio. De ahí se deduce que el mostrar la malformación mientras se gesta, hace al feto más vulnerable a los llamados "derechos de terceros", esto porque aun cuando se le negara la calidad de ser viviente o perteneciente a la especie humana a este feto anencefálico, como algunos quisieran demostrar, es un hecho que desde el momento que ya ha nacido no afectaría de manera importante a eventuales derechos de otros, y nadie se opondría a dejarlo existir su corto lapso de vida natural otorgándole sólo los cuidados básicos. Situación, como ya lo dijimos, que cambia mientras permanece en el útero de una mujer.

Sabemos que actualmente el útero puede no ser un lugar tan seguro como solía ser. Si no es seguro para un feto sano, menos lo será para un ser que presenta dudas incluso en su calidad de viviente 0 perteneciente a la estirpe humana. En algunas latitudes se procura la muerte de un embrión o feto por razones tan nimias como no ser de un determinado sexo, o simplemente sin mayores razones que la voluntad de hacerlo, entonces es fácil comprender la fragilidad de su existencia intrauterina.

Es necesario, entonces, para poder instituir la relación que debemos tener como madres, padres, médicos, abogados o simplemente ciudadanos con este existente intrauterino, establecer cuál es su verdadero estatuto existencial. Ya una vez resuelto este aspecto, deberemos hacer un análisis sobre sus derechos, y cómo resolver, si los hubiera, eventuales conflictos de intereses con los distintos componentes de nuestra sociedad.

\section{EL FETO ANENCEFÁLICO COMO CADÁVER}

Se han planteado hipótesis respecto a la calidad de realidad de este feto intrauterino. Una de ellas sostiene que no es un ser vivo, o que estanía muerto. Esta opinión se funda en la aceptación de la muerte encefálica como criterio de muerte de un individuo; si se considera muerto un sujeto en estado de muerte cerebral, entonces, por simple lógica, un individuo sin cerebro lo estaría también. Si aceptamos esta tesis, una mujer portando un embarazo con un feto anencefálico estaría entonces en la misma condición de otra con un aborto retenido, término obstétrico que se refiere a un embrión muerto in utero, que tiene clara indicación médica de evacuar de esa mujer el contenido uterino. 
La muerte cerebral como criterio de muerte de un sujeto, nació en 1968 en un informe de un comité de la Escuela de Medicina de Harvard, integrado por médicos, abogados y teólogos, quienes postularon que pacientes que estaban en lo que se conoce como "coma irreversible" se podían considerar en "muerte encefálica". Ellos propusieron que la muerte encefálica correspondía al cese irreversible y completo de todas las funciones encefálicas; que la muerte encefálica podía ser diagnosticada y que un paciente en muerte encefálica podía ser considerado muerto*. El comité de Harvard, con estos tres postulados, hizo por primera vez equivalente los términos de muerte encefálica y muerte del individuo total: "nuestro principal propósito es definir el coma irreversible como un nuevo criterio para la muerte".

En una primera mirada, si aceptamos este criterio de muerte, parece tentador aplicarlo a un feto anencéfalo. Sin embargo, con una mayor detención veremos que no es posible. El concepto de muerte encefálica exige que todas las funciones encefálicas estén irreversiblemente abolidas, y esto significa que un individuo en ese estado no puede tener movimientos respiratorios ni poseer reflejos. Son entonces sujetos que están necesariamente inmóviles y conectados en un respirador, ya que sin él pasarían rápidamente a cumplir el criterio clásico de muerte, es decir un paro cardiorrespiratorio. Mas los que atendemos a mujeres embarazadas con fetos anencefálicos sabemos que éstos son móviles y que al nacer no sólo respiran espontáneamente y tienen reflejos, sino que también pueden deglutir los alimentos, pudiendo vivir horas, días e incluso semanas, sin necesidad de respirador artificial. Los fetos anencefálicos no están entonces muertos. No cumplen ni el criterio clásico de muerte al poseer un corazón latiente, ni el nuevo criterio de muerte encefálica. Son entonces, por simple deducción, seres vivos.

\section{CONDICIÓN DE HUMANIDAD DEL ANENCEFÁLICO}

La segunda hipótesis que se ha planteado respecto al estatuto del feto anencefálico es la que postula que, estando vivos, no se les puede considerar personas, es decir, consiste en comprenderlos como seres vivos, pero no verdaderamente humanos. Parece comprensible y muy fácil negarle el estatuto de humano, ya que no ejerce y no ejercerá nunca las propiedades más propias de nuestra especie. Si consideramos que lo que especifica y determina a un ser vivo como homo sapiens es justamente su capacidad de razonar, de determinarse sus propios fines y por lo tanto de ser libre, es evidente que el feto anencefálico carece de todo esto. Sin embargo, no es por carecer de esas propiedades -condición que compartiría de hecho con todo embrión o feto-, sino que la seguridad acerca de que no las podrá ejercer, lo que lo despojaría de su condición humana. El feto anencefálico entonces, según esta postura, no sería humano, porque nunca podrá ejercer las facultades que a éstos caracterizan.

La pregunta que aparece rápidamente para desvirtuar esta posición, es si debemos considerar como perteneciente a la especie humana sólo al que ejerce en acto estas facultades, $0 \mathrm{al}$ menos al que tiene la posibilidad de ejercerlas alguna vez. Si respondemos afirmativamente a la pregunta, le quitaríamos en un instante la condición de humanos a muchos individuos que la sociedad tiende en general a proteger, como son los discapacitados mentales profundos o los pacientes en estado vegetativo persistente. De manera que, una vez más, no podemos conceder tan fácilmente la validez de esta segunda premisa, porque estos dos grupos recién aludidos, concitan en general atención y preocupación como grupos vulnerables de una comunidad $\mathrm{y}$, sin embargo, ninguno de los dos ejerce las facultades ya enunciadas propias de los seres humanos.

\footnotetext{
* Report of the Ad-hoc Committee of the Harvard Medical School to examine the definition of Brain Death. A definition of irreversible Coma. JAMA 1968; 205: 337-40.
} 
Pareciera por lo tanto, haber algo más que las meras facultades en los seres que aparecen a la existencia, después de la unión de gametos provenientes de progenitores humanos. Algo que, más allá de que razonemos o no lo hagamos, nos hace a todos por igual dignos de un mismo respeto y dignidad.

Recurrir al genoma o a la composición genética como estructura especificadora de lo humano, viene a ser, aunque atractivo, también un recurso bastante pobre para esta reflexión, porque si fundamos la pertenencia a la especie con el criterio de poseer 46 cromosomas, tendríamos que decir que efectivamente un feto anencefálico es un ser humano porque sí los tiene. Mas reconocemos como seres humanos a muchos individuos que no cumplen con ese criterio, ejemplos de ellos son los poseedores de un cromosoma extra, como la trisomía 21 o síndrome de Down, el síndrome de Klinefelter y el de Turner, por nombrar los más frecuentes. Existen muchas otras alteraciones genéticas con fenotipos mucho más alterados que el de los nombrados que mantienen, sin embargo, la dotación "humana" de los cromosomas. Entonces, vemos que la adecuada dotación de cromosomas y genes es otro criterio muy insuficiente para determinar la humanidad de una entidad. Además, para reconocer a un sujeto como perteneciente a la especie humana nunca hemos recurrido a la visualización de sus cromosomas. Más aún, a todos consta que se identificaban a los humanos, a los monos y a las moscas como tales, mucho antes que se conociera la existencia de cromosomas, genes y moléculas de ADN. Entonces, recurrir a este criterio del genoma implica no considerar como humanos a todos los que lo son y, por otra parte, no todo lo que tiene una dotación de 46 cromosomas se puede considerar un individuo humano; un cultivo de tejidos o un órgano a trasplantar, teniendo sus células 46 cromosomas, no son, definitivamente, individuos de nuestra especie.

Tendremos que responder entonces ¿qué es lo que hace que algo sea un ser humano? Y luego de dilucidar esta crítica pregunta, tendremos que contestarnos si un feto anencefálico cumple con esa condición.

¿Será su aspecto? El tema del aspecto como criterio identificador de un individuo que postula a la humanidad es bastante interesante. De hecho, en las realidades artificiales (no naturales), el aspecto o figura determina radicalmente lo que un objeto es. El David es el David y no el Moisés, no por el mármol o materia donde está plasmado, sino por la idea, figura o forma que Miguel Ángel traspasó desde su mente a esa materia adecuada para recibirla; es decir, lo que hace que un objeto sea lo que es, es algo inmaterial que crea y traspasa el artista 0 artesano a una materia*. Todos los artefactos creados por el hombre son lo que son por esa "idea", que existe primero en la mente de alguien y que aparece en la existencia cuando se plasma en un material apropiado. Siguiendo la misma línea, nada impide que los seres vivos sean lo que son por un principio también inmaterial, que in-forma de distinta manera a la materia común, incluida las moléculas de ADN, que todos los vivientes compartimos. Esa misma materia recibirá un principio que constituirá unas veces humanos y otras veces otros seres vivos.

Ahora bien, si torpe e hipotéticamente comenzáramos a destruir la figura del David, llegaremos a un punto en que éste dejaría de serlo, es decir su aspecto no sería ya el ideado por Miguel Ángel. Podemos decir entonces que el David dejaría de ser el David si destruyéramos su figura, de la misma manera, por ejemplo, que una mesa -artefacto artificial creado por el hombre-, deja de serlo, o deja de existir como mesa, al perder todos sus pilares o soporte.

Pero en los seres humanos ies el aspecto o figura lo importante para pertenecer a la especie? La desfiguración de un anencéfalo dio podría hacer perder su humanidad? En una primera mirada, podemos notar que es muy desemejante a otro feto humano sano, tan desemejante como podría serlo un hombre que a consecuencia de un incendio queda con su rostro desfigurado e irreconocible, $\mathrm{u}$ otro que por nacimiento o accidente no posee sus extremidades. Tenemos la-

\footnotetext{
*Fue Aristóteles el que para explicar la realidad siempre cambiante, concibió a los seres constituidos por una materia - posibilidad de ser- y su forma -lo que le otorga el ser de esa manera-. Aristóteles Física caps. 1 y 2 . Nota de los autores.
} 
mentablemente variados ejemplos de estos casos, mas en ninguno de ellos hemos llegado siquiera a pensar en despojarlos de su característica de humanos. ¿Cómo o por qué podría entonces con un feto anencefálico ser diferente?

Existe por supuesto una desfiguración que nos haría no ser humanos, pero ésta deberá ser mucho más profunda y radical que cambios tan dramáticos como podrían ser la pérdida de un brazo 0 piernas. La única posible desfiguración que nos podría llegar a despojar de nuestra humanidad es la que nos provoca la muerte. De la misma manera, el único cambio que nos otorga esa humanidad es el que nos otorga la vida. Somos humanos entonces todos los que hemos recibido esa forma que nos otorgó esa manera de existir, independientemente de otros cambios que padecemos natural o accidentalmente en el transcurso de nuestra existencia.

Así como un embrión es humano no habiendo desarrollado aún un cerebro, así como un discapacitado mental es humano aunque su cerebro esté dañado y no puede expresar lo más característico de su humanidad, así como un niño con un síndrome de Down es humano aunque no tenga el genoma característico, un feto con este gran defecto en su estructura encefálica también comparte con todos nosotros la pertenencia a la humanidad y es, por lo tanto, digno del mismo respeto.

\section{AdECUADO TRATO DEL FETO ANENCEFÁLICO}

Nos haremos por último cargo de algunos argumentos que, aceptando el estatuto de ser humano vivo del feto anencefálico, consideran lícita la interrupción de esos embarazos fundamentalmente por dos razones, casi siempre entrelazadas: la primera es que hay plena certeza de que el feto va a morir, si no dentro del útero, a poco tiempo de nacer. La segunda, porque el gestar en su interior un feto de estas características y de este pronóstico le causaría a la madre un sufrimiento psicológico que cesaría al provocarse el aborto. Como vemos, la primera razón es de tipo eugenésica y la segunda de índole terapéutica para la madre. La argumentación sería de este tipo: ¿Para qué seguir con este embarazo, que le está causando angustia a la madre, si igual el feto va a morir por su grave malformación?

Pareciera una solución sumamente práctica. Se terminaría el problema de la madre y al feto sólo se le adelantaría su muerte, hecho del cual ni siquiera se daría cuenta. Sin embargo, lo que provoca una enorme inconformidad en esta solución es que, si somos consecuentes y aceptamos la igualdad de respeto a los derechos elementales de todo ser humano, parece ser una solución injusta para este sujeto en esa lamentable condición. Además, y esto podría ser motivo de otra reflexión, es por lo menos discutible que provocar el aborto efectivamente produzca un efecto curativo a la madre.

A estas alturas de la historia de la humanidad, deberíamos hacer esfuerzos para solucionar los problemas evitando matar a seres inocentes, por muy lamentable que a ojos de terceros sea su manera de existir. Hay diametralmente otra manera de enfrentar esta situación que, lo sabemos, está afectando profundamente a esa mujer embarazada. Consideremos a ese feto como lo que realmente es: para esa mujer es su hijo enfermo, para el médico que consulta es su paciente y para toda la comunidad es un miembro de la sociedad con una importante discapacidad. Otorguémosle entonces a la madre, consecuentemente, el cuidado y apoyo que merece y requiere. Hagamos los esfuerzos necesarios para que comprenda que su hijo enfermo vivirá lo que su potencialidad de vida le permita, y que es importante que lo cuide en su interior ese tiempo. Al feto enfermo, por su parte, otorguémosle lo que le corresponde, el respeto a su vida hasta que la pierda naturalmente, entregándole al nacer los cuidados proporcionados que como todo individuo humano merece.

Los médicos que hemos tenido la experiencia de controlar y tratar a estos dos pacientes -la madre y su hijo- vemos que este apoyo le entrega a ella y a toda la familia la gran tranquilidad de haber cuidado y hecho lo posible por su hijo; y, a todos los que de alguna manera se relacionan con ellos, la certeza de haber actuado de una manera justa y solidaria. 


\section{REFERENCIAS}

1. Hochberg L, Stone J. Prenatal screening and diagnosis of neural tube defects. En: Uptodate versión 15.1, 2006.

2. Fishman M, Viшarreal G. Anencephaly and encephalocele. En: Uptodate versión 15.1, 2006.
3. Monteagudo A, Timor-Tritsch I. Ultrasound diagnosis of neural tube defects. En: Uptodate versión 15.1, 2006.

4. Detrait E, George T, Etchevers E, Gilbert J, Vekemans M, SPEERS. Human neural tube defects: Developmental biology, epidemiology, and genetics. Neurotoxicology and Teratology 2005; 27: (2005) 515-24. 